'As a trainer, it gave me great insight in to trans-cultural practices and their implication on mental health- This has improved my confidence in dealing with and discussing mental health issues with local Somali diaspora whilst being culturally sensitive at the same time.'

\section{Options moving forwards}

The principal, and most natural, next step would likely be in furthering the MCFT partnership with $\mathrm{HMHF}$, and facilitating continued distance learning. This would be directly linked to exploring the capacity for establishing a secure, neutral site within southern Somalia in which face-to-face training could be instigated. Furthermore, as suggested by the programme coordinator in Somalia, procuring accreditation would potentially incentivise reluctant participants and act to further raise the public profile of mental health in the country. Finally, such programmes can help give insight into the cultural understanding of mental health problems and possibly help us to evaluate the extent of the psychiatric morbidity within the Liverpool-based Somali diaspora. Research into this area could possibly identify any unmet healthcare needs. If this was the case, plans could then be drawn up to meet these needs.

\section{References}

Hooper R. (2013) Where hyenas are used to treat mental illness. BBC News [online], 17 October. Available at http://www.bbc.co.uk/news/ magazine-24539989 (accessed 4 February 2017).

Tropical Health and Education Trust (THET) (2002) Kings-THET Somaliland Partnership (KTSP). THET. Available at https://www.rcpe.ac. uk/international/kings-thet-somaliland-partnership (accessed 4 February 2017).

World Health Organization (WHO) (2010) A Situation Analysis of Mental Health in Somalia. World Health Organization. Available at http://applications.emro.who.int/dsaf/EMROPUB_2010_EN_736.pdf (accessed 4 February 2017).

World Health Organization (WHO) (2011) Mental Health in Somalia. World Health Organization [online]. Available at http://www.who.int/ hac/crises/som/somalia_mental_health/en/ (accessed 28 January 2017).

World Health Organization (WHO) (2013) Building Back Better: Sustainable Mental Health Care After Emergencies. World Health Organization. Available at http://www.who.int/ mental_health/emergencies/building_back_better/en/ (accessed 4 February 2017).

World Health Organization (WHO) (2015) Somalia. World Health Organization [online]. Available at http://www.who.int/countries/som/ en/ (accessed 4 February 2017).

Worldometers.info (2017) Somalia Population (2017). Worldometers. info [online]. Available at http://www.worldometers.info/

world-population/somalia-population/ (accessed 4 February 2017).

\title{
SPECIAL PAPER \\ A qualitative study assessing the feasibility of implementing a group cognitive-behavioural therapy-based intervention in Sierra Leone
}

\author{
Samantha Waterman, ${ }^{1}$ Charles L. Cole, ${ }^{2}$ Neil Greenberg, ${ }^{3}$ G. James Rubin ${ }^{4}$ \\ and Alison Beck ${ }^{5}$
}

${ }^{1}$ Assistant Psychologist, South London and Maudsley NHS Foundation Trust, UK; email Foundation Trust, UK; email
samantha.waterman@nhs.net ${ }^{2}$ Assistant Psychologist, Division of Psychiatry, University College

London, UK

${ }^{3}$ Professor of Defence Mental Health, Institute of Psychiatry, Health, Institute of Psychiatry, Psychology and Neuroscience,
King's College London, UK "Reader in the Psychology of Emerging Health Risks, Institute of Psychiatry, Psychology and
omerging Health Risks, Institute Neuroscience, King's College London, UK

${ }^{5}$ Head of Psychology and Psychotherapy, South London and Maudsley NHS Foundation Trust, UK

Acknowledgements. We thank Idit Albert, Annis Cohen, Sarah Coleman, Jennifer Foster, Jennife House, Elaine Hunter, Mary Ion, Alison Jones, Ukwuori-Gisela Kalu, Kathy Nairne, Clare Reeder, Andy Sweeting, Klya Vailancourt and
Mental health support in Sierra Leone is sparse, and qualitative research into the feasibility of implementing psychological interventions is equally underdeveloped. Following the 2014 Ebola virus disease outbreak, South London and Maudsley NHS Trust were commissioned to develop a psychological intervention that UK clinicians could train national staff with minimal psychological experience to deliver to their peers. Following the completion of the stepped care, group-based cognitivebehavioural therapy intervention, qualitative interviews were conducted with the national team to identify key barriers and enablers to implementation of and engagement with this intervention. This article describes the key themes that came out of those interviews, and discusses the implications of these findings for future clinical teams.
Mental health support in Sierra Leone is largely limited to support from families, local communities and traditional healers (Alemnu et al, 2012). There is no modern mental health legislation and no specific budget for mental health (WHO, 2010). In addition, there are high levels of stigma surrounding mental ill-health.

During the 2014-2015 Ebola virus disease (EVD) outbreak in West Africa, Ebola treatment centres (ETCs) were set up across Sierra Leone and staffed by a combination of national and international healthcare workers. These staff were exposed not only to significant risk of infection with the disease, which is highly contagious (Gulland, 2014), but also to traumatic scenes of human suffering on a daily basis (Paladino et al, 2017). There is a significant body of evidence that experiencing trauma increases a person's susceptibility to mental health difficulties (Thormar et al, 2013; West et al, 2008). 

Open Access article, distributed under the terms of the Creative Commons Attribution-

NonCommercial-NoDerivatives licence (http://creativecommons. org/licenses/by-nc-nd/4.0/), which permits non-commercial re-use permits non-comnercial re-use, distribution, and reproduction in any medium, provided the original work is unaltered and is properly cited. The written permission of Cambridge University Press must be obtained for com mercial re-use or in order to create a derivative work.
Following the EVD outbreak, South London and Maudsley NHS Trust trained a team of ex-ETC staff to deliver a group-based cognitivebehavioural therapy (CBT) intervention targeting anxiety and depression, to support their peers from the ETCs. Qualitative interviews were later conducted with the facilitators to gain a more in-depth understanding of the barriers and enablers to engagement within this population.

\section{Intervention and setting}

Twelve national ex-ETC staff were trained to facilitate the delivery of this intervention with their peers. All 12 CBT facilitators received weekly support and coaching from a UK-based psychologist or psychotherapist via Skype.

The intervention developed was a 6-week group CBT programme for depression and anxiety modelled on the evidence-based low-intensity interventions delivered in the UK (Beck et al, 1979). A total of 253 people were referred to the CBT programme, and 157 (62\%) completed the full intervention. Although the majority of participants were literate, some were not, and all written material was adjusted accordingly.

\section{Participants}

Owing to the high level of consensus throughout the interviews, it was agreed that data saturation had been reached after ten interviews. The participants were nine of the 12 CBT group facilitators and one staff member responsible for assisting in the coordination of the project. Five were female $(50 \%)$ and five were male (50\%).

\section{Procedure}

Each participant was interviewed in English over Skype by one of two researchers based in the UK. Interviews lasted between 45 and $60 \mathrm{~min}$. Ethical approval was received by the Medical Director of South London and Maudsley NHS Trust. Participants were asked open questions designed to highlight the barriers to and enablers of group CBT implementation, such as 'what were the main challenges you as a facilitator faced during the intervention?' and 'what were the things you felt went well during the intervention?'.

\section{Data analysis}

The interviews were recorded and transcribed. These qualitative data were subsequently analysed by two researchers (C.L.C. and S.W.) using thematic analysis.

\section{Results}

\section{Barriers}

Lack of motivation to attend

Most of the facilitators agreed that there was a lack of external motivating factors for attending and engaging with the group CBT sessions. Being provided with treatment itself did not seem to be motivation enough; group participants expected refreshments, and although they were reimbursed for travel, this did not provide substantial motivation.

'Many of the participants... they don't have anything. They were used to being given refreshments... [they] were given transport costs instead, which were worthless ... sometimes I had to beg people to attend sessions'.

Additionally, many of the participants viewed acquiring employment as their priority:

'The participants were more concerned about getting jobs than their mental health. [they were] paid lots for working in the treatment centres - but today they are unemployed'.

\section{Low literacy levels}

Although the materials were adapted for lower literacy levels, many participants still struggled to understand the workbooks. This meant that the sessions were often interrupted and some participants were less able to complete homework tasks and contribute to group discussions.

'It was very challenging to teach CBT to people that could not speak or read English... I had to give them a lot of assistance and sometimes they still wouldn't understand, even when I explained in the local language'.

Differing cultural conceptualisations of mental health problems

Within the Sierra Leonean culture, mental health problems are often conceptualised in ways that differ to the western biopsychosocial model. These can include witchcraft, evil spirits, or curses (Yoldi, 2012, p. 62). Therefore, some participants found it challenging to integrate the novel concepts of CBT into these pre-existing conceptualisations:

CBT is new here and many people struggled to understand the concepts that aren't things like black magic, witchcraft ... some people didn't get the point in coming because they didn't see their problems in the same way we did'.

\section{Resource constraints}

Owing to resource constraints, the final four sessions had to be merged. The resulting two sessions were longer, but some of the content had to be condensed, and facilitators were not able to explain the material in as much depth:

'The participants wanted to drop off because they couldn't understand the sessions. I had less time to explain some important parts'.

\section{Enablers}

Novelty of CBT

Taking part in a CBT programme was novel and exciting for some attendees, leading to heightened engagement.

'CBT was a new experience for them and a new process of learning...the more interested ones answered more questions and were faster to manage their depression'.

\section{Social networks}

Many participants had already met each other in previous parts of this stepped intervention and formed friendships. This greatly enhanced cohesiveness among some of the groups, a factor that 
has been shown to influence the effectiveness of group CBT and the facilitation of a safe space to share (Whitfield, 2010).

'Participants got to make friends in the earlier phases... making them feel safe enough to be honest about their problems that they kept secret due to community stigma and shame'.

\section{Discussion}

This study suggested some key barriers to, but also some enablers of, the implementation of a phased group-based CBT intervention in Sierra Leone. These results add qualitative information about the first-hand challenges that are faced by clinicians attempting to implement psychological interventions in Sierra Leone.

The people of Sierra Leone experience high levels of poverty, and within the sample of the current study, $53.8 \%$ of participants were unemployed. According to Maslow's hierarchy of needs theory (Maslow, 1943), it is understandable that ETC workers, who were unable to find jobs and had been ostracised from their communities, would prioritise their physical and safety needs above attending to their mental health. In other words, they would lack the motivation to attend a group focusing purely on their psychological needs. However, further investigation would be required involving consultation with the attendees to further isolate the individual barriers to engagement.

While this may be a continually present factor in countries like Sierra Leone, where the poverty rate is $77.5 \%$ (United Nations Development Program, 2016), interventions should be implemented using a collaborative psychosocial approach, working with social agencies available in Sierra Leone to not only improve attendees mental health, but also to support them through their social difficulties, including unemployment. Talking therapy interventions such as The Friendship Bench, which also utilise lay health workers, have been shown to be effective in other South African countries (Chibanda et al, 2016), demonstrating the perceived usefulness of talking therapies and the value of psychological approaches similar to this model.

Educating the population about the importance of good mental health and the far-reaching benefits of this may improve people's motivation to attend similar interventions in the future. In addition, providing some form of sustenance such as a small snack may be beneficial in lowincome countries where participants may be hungry, which could affect their concentration and ability to interact in the groups.

This study highlighted the difficulties in implementing psychological interventions in sub-Saharan Africa. However, it also demonstrated some key enablers. The findings may be useful for future research projects and clinical teams to consider. There is some evidence suggesting that many non-Western cultures identify with a 'collective self', whereby the identity and sense of self of a person is defined by their relationships with others - in contrast to the Western 'individual self, in which identity is based on the individual alone (Luhrmann et al, 2015). This may explain the importance of social networks in this population, and offer understanding as to why networks were a key enabler to engagement.

There were two key limitations to this study. First, these data reflect the perceptions of the facilitators about what the group attendees were thinking; without direct questioning of the group attendees themselves, we cannot validate these results. Second, the intervention was implemented within a particularly niche sample. Group attendees had all worked at the ETCs during a traumatic, but specific, crisis, so the barriers to and enablers of engagement in a group CBT programme discussed here may not apply to populations that have not recently experienced similar trauma.

Nonetheless, this study offers a unique insight into the barriers to and enablers of implementing a group-based CBT programme in sub-Saharan Africa, which can be used by future teams to increase uptake in such interventions with this population.

\section{Funding}

Financial support was received from the UK Public Health Rapid Support Team, funded by the UK Government, the UK Department for International Development and the Maudsley Charity. This report is independent research by the UK Public Health Rapid Support Team. The views expressed in this publication are those of the authors and not necessarily those of the National Health Service, the National Institute for Health Research or the Department of Health.

\section{References}

Alemu W., Funk M., Gakurah T., et al (2012) WHO profile on mental health in development (WHO proMIND): Sierra Leone. World Health Organisation.

Beck A., Rush A., Shaw B., et al (eds) (1979) Cognitive therapy for depression. The Guilford Press.

Chibanda D., Weiss H. A., Verhey R., et al (2016) Effect of a primary care-based psychological intervention on symptoms of common mental disorders in Zimbabwe. Journal of American Medical Association, 316(24), 2618-2626.

Gulland A. (2014) UK built Ebola treatment centre opens in Sierra Leone. BMJ, 349, g6704.

Luhrmann T. M., Padmavati R., Tharoor H., et al (2015) Differences in voice-hearing experiences of people with psychosis in the USA, India and Ghana: interview-based study. The British Journal of Psychiatry, 206(1), 41-44.

Maslow A. H. (1943) A theory of human motivation. Psychological Review, 50, 370-396.

Paladino L., Sharpe R. P., Galwankar S. C., et al (2017) Reflections on the Ebola public health emergency of international concern, part 2: the unseen epidemic of posttraumatic stress among health-care personnel and survivors of the 2014-2016 Ebola outbreak. Journal of Global Infectious Diseases, 9(2), 45-50.

Thormar S. B., Gersons B. P., Juen B., et al (2013) Organizational factors and mental health in community volunteers. The role of exposure, preparation, training, tasks assigned, and support. Anxiety, Stress \& Coping, 26(6), 624-642. 
United Nations Development Program (2016) About Sierra Leone. Retrieved from: http://www.sl.undp.org/content/sierraleone/en/home/ countryinfo.html.

West C., Bernard B., Mueller C., et al (2008) Mental health outcomes in police personnel after Hurricane Katrina. Journal of Occupational and Environmental Medicine, 50(6), 689-695.

Whitfield G. (2010) Group cognitive-behavioural therapy for anxiety and depression. Advances in Psychiatric Treatment, 16(3), 219-227.
World Health Organisation (WHO) (2010). mhGAP Intervention Guide for Mental, Neurological and Substance Use Disorders in Non Specialized Health Settings: Mental Health Gap Action Programme (mhGAP). Retrieved from: www.who.int/mental_health/mhgap.

Yoldi O. (2012) Sierra Leone: Trapped in the Shadows of the Mind. Refugee Transitions, 26, 60-65. Retrieved from: http:/ /www.startts. org.au/media/Refugee-Transitions/

Refugee-Transitions-Issue-26-sierra-leone-trapped-in-theshadows-of-the-mind.pdf

\title{
EDITORIAL \\ Global mental health and sustainable development 2018
}

\author{
Rachel Jenkins ${ }^{1,2}$
}

\section{${ }^{1}$ Institute of Psychiatry, Psychology and Neuroscience, King's College London, UK \\ ¿BA (Hons), MB, BChir, MD (Cantab), Institute of Psychiatry, Health Services Research, de Crespigny Park, London SE5 8AF, UK. Email: rachel@olan.org}

Conflicts of interest None.

Keywords. Global mental health; sustainability; service users: mental health services; integrated service provision.

\section{doi:10.1192/bji.2019.5}

c The Author 2019. This is an Open Access article, distributed under the terms of the Creative Commons AttributionComs AtributionCom cence (http://creativecommons. org/licenses/by-nc-nd/4.0/), which permits non-commercial re-use, distribution, and reproduction in any medium, provided the original work is unaltered and is preper mission of Cambridge University Press must be obtained for com mercial re-use or in order to create a derivative work.

\begin{abstract}
The Lancet Commission summarises some of the history of mental health concepts, recent developments in scientific understanding, mental health programmes and threats to progress, and proposes a way forward. Although ostensibly aiming to reframe global mental health within the paradigm of sustainable development, in practice it has taken a narrower academic perspective rather than a generic approach to health and social sector reform, leading to much less of an integrated implementation focus than would have been useful.
\end{abstract}

Three years ago, the UN launched its Sustainable Development Goals (SDGs) to push world leaders into addressing problems such as poverty, hunger and climate change (UN, 2015). The SDGs replaced the earlier Millennium Development Goals (MDGs). These had not specifically included mental health (UN, 2000), although mental health was critically relevant to most of the MDGs, especially those relating to physical health, education and economic development (Gureje \& Jenkins, 2007).

The importance of mental health as an integral part of health in general has long been recognised (WHO, 1946). It was reaffirmed with the Declaration of Alma-Ata (WHO, 1978) that affirmed, for the first time, the critical role of primary healthcare for all. The early establishment of the World Health Organization (WHO) Mental Health Division and the World Federation of Mental Health in 1948 paved the way for attention to global mental health via research, policy, training and advocacy over subsequent decades. Calls for enhanced action on mental health have continued since that time, most visibly by the establishment of World Mental Health Day (10 October), initiated by Mrs Roslyn Carter (wife of the ex-US President Jimmy Carter), which has been celebrated in most countries every year since 1992 .
Unlike the earlier MDGs, the recently published SDGs specifically include mental health. (Box 1). They provide a useful framework for stimulating, monitoring and reviewing global development. The Lancet took the opportunity to produce a Commission on Global Mental Health and Sustainable Development, with a view to assessing the agenda and progress in the context of the SDGs. The report of the Commission contains much of interest to a wide audience. It gives some perspectives on the history of mental health concepts, on recent developments in scientific understanding and on mental health programmes; it assesses threats to progress, including human rights abuses, constrained resources, major demographic transitions and social risk factors; and it emphasises the importance of addressing mental

Box 1. The mental health-related SDGs

$S D G 3.4$ requires states to adopt the following aim: 'By 2030, (to) reduce by one third premature mortality from non-communicable disease (NCDs) through prevention and treatment and promote mental health and well-being'. SDG 3.5 requires states to 'strengthen the prevention and treatment of substance abuse, including narcotic drug abuse and harmful use of alcohol'. Thus, SDG 3.5 and the first part of SDG 3.4 demand policy attention for the prevention and treatment of mental, neurological and substance use disorders, while the second half of SDG 3.4 requires policy attention to be given to mental health promotion.

Other SDGs (especially 1,5, 8 and 10, relating to poverty reduction, gender, economic development and reducing inequalities, respectively) also require attention be paid to mental health, as mental disorders are highly associated with poverty, financial hardship and debt, and low productivity. They are generally more common in women, among ethnic minorities, people with disabilities and other marginalised groups (Foresight 2008; Beddington et al, 2008). 